\title{
Analisis dan Perancangan Software Perhitungan Metrik Skala dan Kompleksitas Web Service
}

\author{
Rizki Fitriani ${ }^{1, *}$, Abd. Qohar Agus Maulana ${ }^{2}$, Lingga Wahyu Rochim ${ }^{3}$, Muhammad Ainul Yaqin $^{4}$ \\ Jurusan Teknik Informatika, Universitas Islam Negeri Maulana Malik Ibrahim, Indonesia \\ ${ }^{1}$ fitriarizki2805@gmail.com; ${ }^{2}$ abdulqoheng@gmail.com; ${ }^{3}$ linggawahyurochim@gmail.com; ${ }^{4}$ yaqinov@ @i.uin- \\ malang.ac.id \\ * corresponding author
}

INFO ARTIKEL

\section{Sejarah Artikel}

Diterima: 3 Oktober 2019

Direvisi: 15 Februari 2020

Diterbitkan: 30 April 2020

\section{Kata Kunci}

Metrik Kompleksitas

Software

Web Service

WSDL

XML

\section{ABSTRAK}

Aplikasi komputer meningkat jumlahnya dan menjadi lebih kompleks seiring dengan pertumbuhan bisnis dan ilmu pengetahuan. Dalam hal ini, pengelolaan dan integrasi data menjadi sangat penting. Pengembangan Web Service semakin meningkat. Pengembang Web Service membutuhkan banyak data riset dan referensi mengenai kompleks atau tidaknya suatu Web Service berkaitan dengan perkiraan biaya pengembangan, batasan waktu pengerjaan, dan sumber daya yang dibutuhkan untuk pengembangan, termasuk spesifikasi komputer dan sumber daya manusianya. Setiap pengukuran yang dilakukan dibutuhkan tersedianya ukuran kuantitatif yang disebut metrik, yang selanjutnya akan menghasilkan output berupa kompleksitas dari Web Service. Atas dasar itu, diperlukan sebuah perangkat lunak yang dapat menghitung metrik skala dan kompleksitas Web Service dengan cara meng-import file bertipe $x m l$ document dan berisi dokumen WSDL (Web Service Description Language) yang digunakan untuk menggambarkan kompleksitas Web Service berdasarkan pengukuran Data Weight (DW) yang dihitung dari bobot Argument per Operation (APO) dan Operation per Service (OPS). Dari percobaan perhitungan kami secara manual terhadap suatu dokumen WSDL, dimunculkan beberapa hasil berupa banyaknya argumen, OPS, dan APO. Hal ini kami terapkan pada perangkat lunak dan menghasilkan proses perhitungan yang lebih cepat. Pengguna dapat meng-import document tipe .xml dan hasil kompleksitas Web Service akan dimunculkan dalam aplikasi. Ukuran metrik dan kompleksitas yang diperoleh dapat digunakan untuk memperkirakan manajemen pengembangan Web Service.

\section{PENDAHULUAN}

Pada era revolusi industri 4.0 ini, perkembangan teknologi dan informasi berkembang begitu cepat. Dengan perkembangan teknologi yang sangat pesat ini, kehidupan masyarakat sering kali terbantu seperti halnya mendapatkan informasi melalui website. Hal ini memungkinkan banyaknya website-website baru yang bermunculan dan tidak sedikit pula website yang menggunakan Web Service. Hal ini dikarenakan Web Service mempermudah suatu komunikasi antar komponen perangkat lunak jarak jauh menggunakan jaringan internet. Ketika World Wide Web diciptakan pada awal 1990-an, tujuan utamanya adalah berbagi dokumen di antara orang-orang, sebagian besar di komunitas ilmiah dan militer. Sejak saat itu, penggunaan Web terus berkembang secara luar biasa. Meningkatnya popularitas Web Service yang didasarkan pada teknologi eXtensible Markup Language (XML) membuat para developer Web Service melakukan kegiatan penelitian untuk mengadopsi pelaksanaan terbaik penerapan Web Service dan menemukan cara yang lebih 
efektif untuk mengelola Web Service [1]. Aliran data antar pengguna harus dikelola dengan baik untuk memberikan konsistensi dalam pertukaran data antara aplikasi melalui pesan.

Sebelum hal tersebut dilakukan, perlu dilakukan perhitungan metrik skala. Metrik skala Web Service adalah bobot atau besaran yang digunakan untuk menghitung tingkat kompleksitas Web Service berdasarkan poin-poin tertentu. Tingkat kompleksitas layanan Web dapat diukur dengan menganalisis dokumen WSDL karena WSDL menyediakan deskripsi Web Service. Namun, WSDL tidak mengandung informasi tentang detail implementasi Web Service, maka yang dapat diukur hanya kompleksitas data Web Service. Kompleksitas data dari Web Service dapat didefinisikan sebagai kompleksitas data yang mengalir ke dan dari antarmuka Web Service dan dapat dicirikan dengan upaya yang diperlukan untuk memahami struktur pesan yang memiliki tanggung jawab untuk bertukar dan menyampaikan data. Dalam hal ini, akan dianalisis struktur message untuk mengukur kompleksitas data Web Service melalui metode pengukuran Data Weight terhadap WSDL [2].

Meskipun banyak metrik perangkat lunak telah dipelajari selama beberapa dekade untuk meningkatkan kualitas perangkat lunak, namun masih sedikit penelitian yang telah dilakukan untuk mengembangkan metrik untuk Web Service sehingga pengembang Web Service akan mengalami kekurangan data dan referensi dalam pemeliharaan Web Service maupun pengembangan Web Service selanjutnya [3]. Pengembang Web Service membutuhkan banyak data riset dan referensi mengenai kompleks atau tidaknya suatu Web Service berkaitan dengan perkiraan biaya pengembangan [4], batasan waktu pengerjaan, dan sumber daya yang dibutuhkan untuk pengembangan, termasuk spesifikasi komputer dan sumber daya manusianya [5]. Setiap pengukuran yang dilakukan dibutuhkan tersedianya ukuran kuantitatif yang disebut metrik, yang selanjutnya akan menghasilkan output berupa kompleksitas dari Web Service [6]. Hal ini menjadi kendala sekaligus motivasi utama untuk meneliti lebih lanjut metrik yang berguna untuk penilaian kualitas kompleksitas Web Service dan mengaplikasikannya dalam bentuk software agar lebih mudah digunakan dan meminimalisir waktu perhitungan metrik skala dan kompleksitas Web Service.

Web Service adalah generasi baru dari aplikasi web. Web Service bersifat mandiri, menggambarkan diri sendiri, aplikasi modular yang dapat dipublikasikan, ditemukan, dan dipanggil di seluruh Web. Web Service menjalankan fungsi, yang bisa berupa apa saja dari permintaan sederhana hingga proses bisnis yang rumit [7]. Web Service sebagai jenis baru aplikasi web menyediakan mekanisme standar umum untuk integrasi sistem-sistem yang berbeda dan telah dapat diterima secara luas oleh berbagai jenis pihak yang terhubung ke internet untuk tujuan yang berbeda [2]. Web Service sendiri menyimpan data informasi dalam format XML, sehingga data tersebut dapat diakses melalui platform yang berbeda, sistem operasi yang berbeda ataupun bahasa pemrograman yang berbeda. Web Service didasarkan pada kumpulan standar dan protokol yang memungkinkan untuk membuat permintaan pemrosesan ke sistem jarak jauh dengan bahasa umum dan menggunakan protokol transportasi umum seperti HTTP dan SMTP. Web Service merepresentasikan pendekatan pemrograman baru berdasarkan pada model berorientasi dokumen yang dirancang untuk interoperabilitas di tingkat dokumen, yang disebut XML. Web Service diimplementasikan menggunakan kumpulan beberapa teknologi terkait dan yang muncul dan protokol komunikasi yang mencakup HTTP, XML, Simple Object Application Protocol (SOAP) [8, 9], Universal Description Discovery and Integration (UDDI), Web Services Description Language (WSDL), Common Object Request Broker Architecture (CORBA), Java Remote Method Invocation (RMI), dan NET [10].

Model layanan web terdiri dari tiga entitas, penyedia layanan, registrasi layanan, dan konsumen layanan. Gambar 1 menunjukkan representasi grafis dari model Web Service tradisional: 


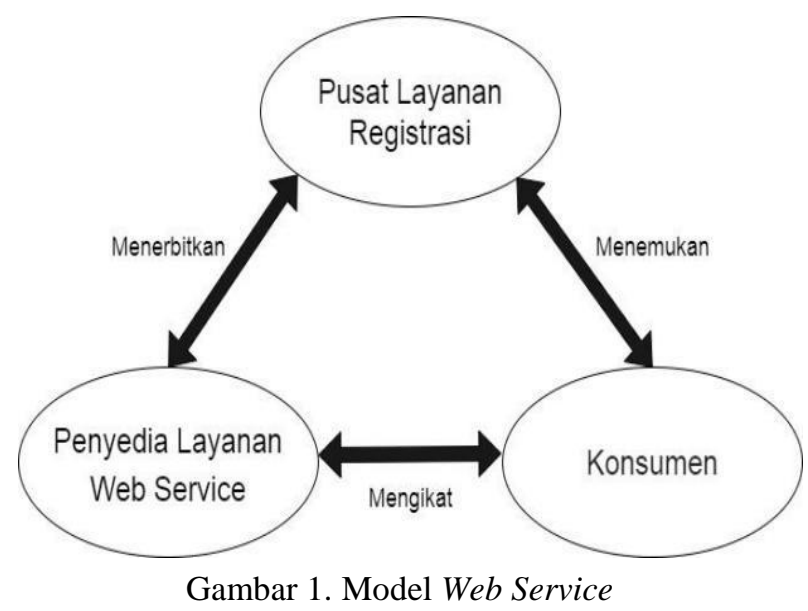

Pada Gambar 1, digambarkan penyedia layanan membuat atau hanya menawarkan Web Service. Penyedia layanan perlu menjelaskan Web Service dalam format standar, yaitu XML dan menerbitkannya di pusat Layanan Registrasi. Pusat Layanan Registrasi layanan berisi informasi tambahan tentang penyedia layanan, seperti alamat dan kontak perusahaan penyedia, dan rincian teknis tentang layanan. Konsumen mengambil informasi dari pusat Layanan Registrasi dan menggunakan deskripsi layanan yang diperoleh untuk mengikat dan meminta layanan Web Service.

Meskipun teknologi Web Service telah diadopsi oleh vendor perangkat lunak besar, seperti IBM, Microsoft, Oracle, Borland, dan menghasilkan sejumlah besar kegiatan penelitian, masih diperlukan penelitian pada metrik Web Service. Sebagian besar pekerjaan difokuskan pada kualitas layanan. Pekerjaan lain difokuskan pada proyeksi metrik yang ada untuk komponen perangkat lunak berorientasi objek [1] pada sistem Layanan Web, karena layanan web sebagian besar dihasilkan dari Object Oriented Programming (OOP) atau Pemrograman Berorientasi Objek. Metrik Web Service sangat berguna untuk pengembang, penyedia, dan pengguna. Pengembang akan menggunakan metrik untuk mengelola dan mengendalikan cara terbaik untuk mengimplementasikan sistem. Penyedia layanan dapat menggunakan metrik untuk memastikan layanan berjalan sesuai dengan langkah-langkah yang ditetapkan, dan pengguna dapat menggunakan metrik tertentu untuk memilih penyedia service atau layanan terbaik. Jadi, penggunaan metrik akan sangat mungkin berbeda berdasarkan siapa yang menggunakannya, dan masing-masing mungkin akan memiliki persyaratan dan tingkat kepentingan yang berbeda.

\section{METODE}

Berdasarkan penelitian yang kami lakukan, Metrik Web Service dapat dihitung menggunakan bobot dokumen WSDL dan Skema XML [3].

\section{Dokumen WSDL}

Semua informasi yang diperlukan untuk meminta Web Service harus diuraikan dengan jelas dan tersedia agar konsumen atau pengguna dapat dengan mudah mengakses dan memproses informasi tentang layanan tersebut. Untuk tujuan ini Web Services Description Language menyediakan model dan format XML untuk menggambarkan Web Services. WSDL 1.1 diajukan ke W3C pada akhir 2001, dan Web Service Description Working Group W3C dibentuk pada awal 2002 untuk menstandarisasi WSDL. WSDL 2.0 adalah versi standar WSDL yang mencakup perubahan dan peningkatan signifikan. Dengan membuat dokumen WSDL, pemilik Web Service dapat memisahkan deskripsi fungsionalitas abstrak 
yang ditawarkan oleh layanan dari detail konkrit deskripsi layanan seperti "bagaimana" dan "di mana" ditawarkan fungsionalitas itu. Ketika integrasi beragam aplikasi ditujukan, Web Service yang terekspos harus dirancang untuk memiliki persetujuan yang ringkas dan jelas tentang spesifikasi umum dari protokol dan sistem tipe data yang dapat digunakan oleh beragam bahasa pemrograman untuk bekerja dengan cara yang dapat dioperasikan. Format pesan atau message yang dipertukarkan antara penyedia layanan dan konsumen harus didefinisikan dengan baik sehingga pengirim pesan dapat dengan mudah membangun dan penerima pesan dapat dengan mudah memproses. Penggunaan dokumen WSDL dan Skema XML diamanatkan untuk menggambarkan layanan Web. Dengan cara ini, interoperabilitas pada lapisan deskripsi layanan dapat dipahami dengan pasti.

\section{Skema XML}

Seperti yang telah disebutkan, aliran data antar aplikasi harus dijaga dengan baik untuk memberikan konsistensi dalam data aplikasi yang disampaikan oleh pesan input dan output dari Web Service dalam interaksi. Untuk menyediakan sistem tipe data umum dan untuk mewakili data aplikasi, dokumen WSDL didukung oleh Skema XML yang diimpor ke atau disematkan ke dalam dokumen WSDL dan dienkapsulasi oleh <types> konstruksi WSDL. Mewakili data aplikasi dengan skema memerlukan pengambilan keputusan strategis yang mempertimbangkan beberapa masalah desain yang harus ditangani pada waktu desain, seperti kinerja, ekstensibilitas, penggunaan kembali, akses data, dan lain sebagainya [18].

Dalam konteks XML, representasi data dibuat dengan merancang skema yang dapat ditulis dalam berbagai bahasa skema XML seperti DTD, W3C XML Schema, dan RELAX. W3C XML Schema dan DTD adalah bahasa skema adalah yang paling sering digunakan untuk menghasilkan dokumen XML. Namun, menyebarkan dokumen XML adalah masalah tantangan untuk aplikasi yang tidak menggunakan teknologi skema pendukung. Agar dokumen XML dapat memberikan pemahaman umum tentang pertukaran data antara aplikasi, dokumen XML ini harus divalidasi terhadap definisi skema XML (XSD). Aspek nyata yang paling penting dari skema XML adalah bahwa skema XML menentukan kontrak antara aplikasi perangkat lunak atau antara bagian dari aplikasi perangkat lunak. Dalam aplikasi web terdistribusi besar, gagasan kontrak memberikan banyak manfaat seperti menyederhanakan modularisasi, alokasi sumber daya, pengujian, dan penyebaran. Menggunakan skema tidak hanya memberikan pemahaman umum tentang data yang dipertukarkan tetapi juga kemampuan metode akses mudah untuk dokumen XML untuk divalidasi. Dengan suksesnya desain dan implementasi skema, para pengembang dapat memiliki kemampuan untuk meningkatkan produktivitas, meningkatkan keandalan perangkat lunak, meminimalkan waktu pengembangan, dan mengurangi waktu untuk penyebaran ke pasar. Mengabaikan skema menyiratkan bahwa validator skema tidak digunakan untuk menentukan apakah dokumen XML yang diberikan memenuhi data yang diinginkan untuk diangkut antar aplikasi. Dalam kasus ini, pemeriksaan yang diperlukan harus dilakukan oleh program aplikasi yang menyiratkan bahwa developer aplikasi harus menulis kode yang panjang. Semua pertimbangan ini menyiratkan bahwa, keputusan dalam desain skema XML untuk mewakili data aplikasi yang dipertukarkan dapat mempengaruhi pemahaman pesan yang dipertukarkan yang dijelaskan dalam dokumen WSDL dan pemahaman layanan Web yang ditentukan oleh dokumen WSDL [19].

\section{Perhitungan Metrik}

Dalam perangkat lunak pengukuran metrik skala dan kompleksitas Web Service, metode yang diterapkan adalah membandingkan Web Service dengan komponen perangkat lunak lainnya dengan mengadopsi beberapa metrik yang ada ke dokumen WSDL, yang dikembangkan untuk mengukur kompleksitas antarmuka komponen perangkat lunak [8]. 
Bagian-bagian yang dihitung dalam penghitungan metrik skala dan kompleksitas Web Service berdasarkan dokumen WSDL adalah sebagai berikut:

\section{Argument per Operation (APO)}

Argument per Operation adalah jumlah argument yang diberikan $\left(\mathrm{n}_{\mathrm{a}}\right)$ dibagi dengan jumlah total operasi $\left(\mathrm{n}_{\mathrm{o}}\right)$ yang dijelaskan dalam WSDL digunakan untuk mengukur ukuran Web Service dan didefinisikan sebagai:

$\mathrm{APO}=\frac{\mathrm{n}_{\mathrm{a}}}{\mathrm{n}_{\mathrm{o}}}$

\section{Operation per Service (OPS)}

Serupa dengan operasi OO metrik WMC (Weight Method Per Class) per layanan didefinisikan sebagai jumlah total operasi yang dinyatakan oleh PortType Web Service dan dimaksudkan untuk mengukur ukuran dokumen WSDL yang diberikan [12].

\section{Data Weight WSDL (DW(wsdl))}

Data Weight dari WSDL yang diberikan dapat didefinisikan sebagai jumlah dari kompleksitas data dari setiap pesan input dan output. Dengan menganalisis struktur pesan (message) yang berisi argument yang diambil oleh operation dari Web Service, kita dapat mengukur kompleksitas data setiap pesan. Secara intuitif, orang dapat menganggap bahwa ketika jumlah operasi dan jumlah argument meningkat, maka pemahaman layanan Web menjadi lebih sulit. Metrik APO (Argument per Operation) dan OPS (Operation per Service) dimaksudkan untuk mengukur kompleksitas antarmuka Web Service yang diberikan [12]. Namun, hal ini tidak selalu terjadi karena argument mungkin memiliki struktur tipe data yang berbeda yang diungkapkan oleh komponen skema XSD dan mungkin memerlukan usaha yang berbeda untuk memahami. Untuk mengukur kompleksitas data dari pesan yang diberikan, kompleksitas data dievaluasi dari elemen-elemen bagiannya yang menggambarkan argument. Kompleksitas data dari setiap elemen bagian dapat tercermin dengan menetapkan Data Weight yang didasarkan pada kompleksitas dari struktur data argument. Arsitektur internal, tingkat kerumitan elemen, tipe yang didefinisikan atau dideklarasikan dalam skema XSD dapat bervariasi dan diberi nilai bobot terkait kompleksitasnya. Karena komponen XSD ini dikaitkan dengan argument untuk menggambarkan struktur data argument, penting untuk menetapkan nilai bobot untuk argument yang sama dengan nilai bobot komponen XSD yang terkait sehingga kompleksitas argument dari struktur datanya akan tampak. Dengan menjumlahkan nilai bobot setiap elemen bagian yang dimiliki oleh konstruksi message WSDL, data kompleksitas message dapat dievaluasi. Akibatnya, total kompleksitas data dari WSDL dapat dievaluasi dengan merangkum kompleksitas data dari semua message. Selanjutnya digunakan metrik Data Weight of WSDL (DW (wsdl)) untuk mengetahui kompleksitas data dokumen WSDL, yaitu upaya yang diperlukan untuk memahami tipe data dari argument yang diambil oleh operasi yang disediakan oleh Web Service [20].

Diberikan dokumen WSDL yang memiliki total message sejumlah $\mathrm{n}_{\mathrm{m}}$, bobot metrik WSDL didefinisikan sebagai: 


$$
D W(w s d l) \doteq \sum_{i=1}^{n_{m}} C\left(M_{i}\right)
$$

$\mathrm{C}\left(\mathrm{M}_{\mathrm{i}}\right)=$ nilai kompleksitas message ke-i dan dapat dievaluasi oleh:

$$
C(M)=\sum_{j=0}^{n_{p}-1} W P_{j}
$$

Dimana $\mathrm{n}_{\mathrm{p}}$

adalah jumlah total elemen <part> yang dienkapsulasi oleh konstruksi pesan atau message yang diberikan, dan merupakan nilai bobot dari <part> ke-i definisi pesan yang ditukarkan.

Argument yang terkandung oleh elemen bagian dari pesan dikaitkan dengan definisi elemen atau deklarasi atau tipe definisi skema XSD. Karena setiap definisi elemen atau tipe dalam skema XSD ditetapkan ke nilai bobot yang mencerminkan tingkat kerumitannya dan dikaitkan dengan argument, $w_{\mathrm{i}}$ memiliki nilai bobot yang sama dengan definisi elemen atau tipe yang terkait dari skema XSD. Sehingga:

wp = we, jika <part> mempunyai elemen yang berhubungan dengan skema deklarasi elemen

$=\mathbf{w t}$, jika $<$ part $>$ mempunyai tipe yang berhubungan dengan skema definisi elemen

$=0$, jika pesan atau message tidak mengandung elemen <part>

di mana $\boldsymbol{w} \boldsymbol{e}$ adalah nilai bobot dari deklarasi elemen terkait dan, $\boldsymbol{w} \boldsymbol{t}$ adalah nilai bobot dari definisi tipe terkait dalam skema XSD yang disematkan atau diimpor ke WSDL. Kompleksitas setiap definisi tipe dalam skema berbeda sesuai dengan strukturnya. Maka:

wt $=$ wc, jika $\langle$ type $>$ adalah definisi tipe kompleks

= ws, jika $\langle$ type $>$ adalah definisi tipe sederhana

\section{Pengembangan Software}

Dalam pengembangan software perhitungan metrik skala dan kompleksitas Web Service, kami menerapkan metode dari Model Waterfall. Waterfall atau sering juga di sebut dengan model klasik yang bersifat sistematis, berurutan dalam membangun software, model ini juga seringkali disebut dengan sekuensial linier atau alur hidup klasik [13],[14],[15].

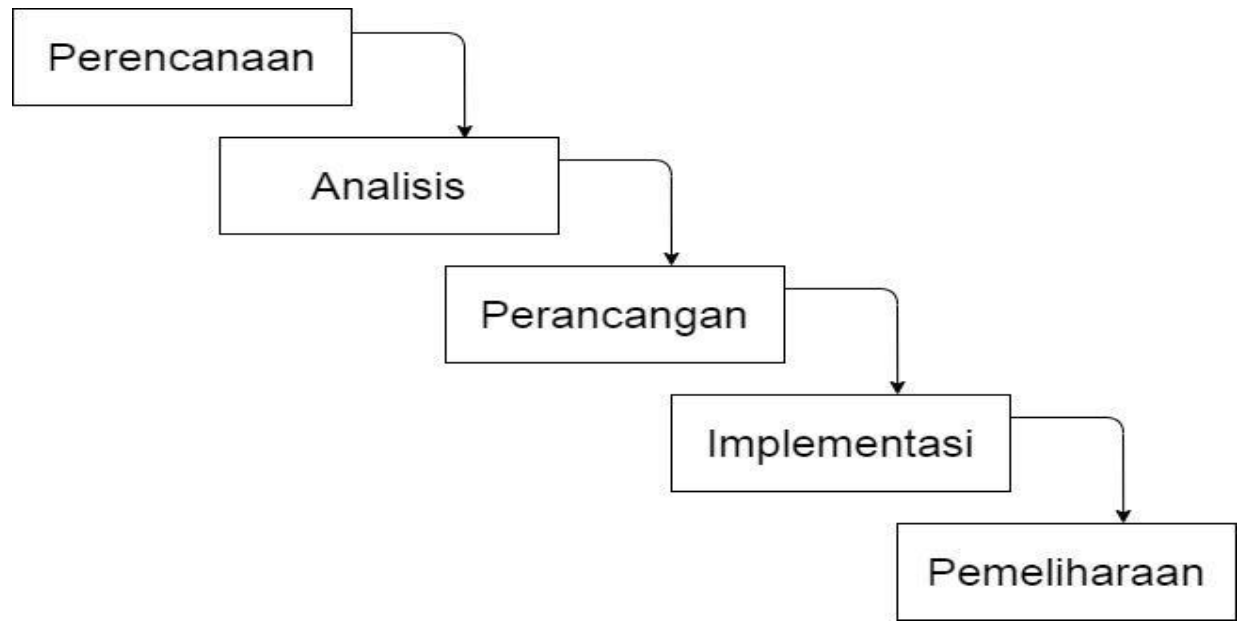

Gambar 2. Model Waterfall 


\section{Perencanaan}

Dalam perencanaan pembangunan software perhitungan metrik skala dan kompleksitas Web Service, kami melakukan penelitian studi literasi pada situs-situs riset dan ilmiah, seperti jurnal, artikel, dan internet, untuk mendapatkan data dan informasi mengenai penghitungan metrik skala dan kompleksitas Web Service. Selain itu, diskusi juga dilakukan oleh beberapa orang untuk bertukar informasi dan ide melalui tanya jawab, sehingga dapat dikonstruksikan makna dalam suatu topik tertentu. Pengumpulan informasi dengan cara mengajukan sejumlah pertanyaan secara lisan dan dijawab secara lisan oleh pihak-pihak terkait demi memahami dan mencapai tujuan yang ingin dicapai. Hasilnya adalah inisialisasi proyek, seperti menganalisis permasalahan yang dihadapi dan mengumpulkan data-data yang diperlukan serta membantu mendefinisikan fitur dan fungsi software. Selanjutnya, didefinisikan setiap proses, mulai dari input, proses perangkat lunak dalam menganalisis Data Weight, dan output dari perangkat lunak.

\section{Analysis (Analisis)}

Layanan sistem, kendala, dan tujuan ditetapkan oleh hasil konsultasi dengan pengguna yang kemudian didefinisikan secara rinci dan berfungsi sebagai spesifikasi sistem [16].

\section{Design (Perancangan)}

Tahapan perancangan sistem mengalokasikan kebutuhan-kebutuhan perangkat lunak dengan membentuk arsitektur sistem secara keseluruhan. Perancangan perangkat lunak melibatkan identifikasi dan penggambaran abstraksi sistem dasar perangkat lunak dan hubungannya [16].

\section{Implementation (Implementasi)}

Pada tahap ini, perancangan perangkat lunak direalisasikan sebagai serangkaian program atau unit program. Pengujian melibatkan verifikasi bahwa setiap unit memenuhi spesifikasinya [16].

\section{Maintenance (Pemeliharaan)}

Tahapan ini merupakan tahapan yang paling panjang. Perangkat lunak dipasang dan digunakan secara nyata. Maintenance melibatkan pembetulan kesalahan yang tidak ditemukan pada tahapan-tahapan sebelumnya, meningkatkan implementasi dari unit perangkat lunak, dan meningkatkan layanan dan fitur perangkat lunak sebagai kebutuhan baru [16].

\section{HASIL DAN PEMBAHASAN}

Dalam pembahasan analisis dan perancangan software perhitungan metrik skala dan kompleksitas Web Service, kami menerapkan perhitungan metrik skala dan kompleksitas Web Service dengan menghitung Data Weight dari dokumen WSDL dan skema XML Web Service tersebut [17].

\section{Perhitungan Manual Metrik Skala dan Kompleksitas Web Service}

Kami melakukan perhitungan metrik skala dan kompleksitas dari dokumen WSDL pada tautan berikut http://www.elguille.info/NET/WebServices/HolaMundoWebS.asmx. Jumlah argument (\#A) dari WSDL dapat dihitung dari banyaknya input message dan output message dari dokumen WSDL tersebut: 


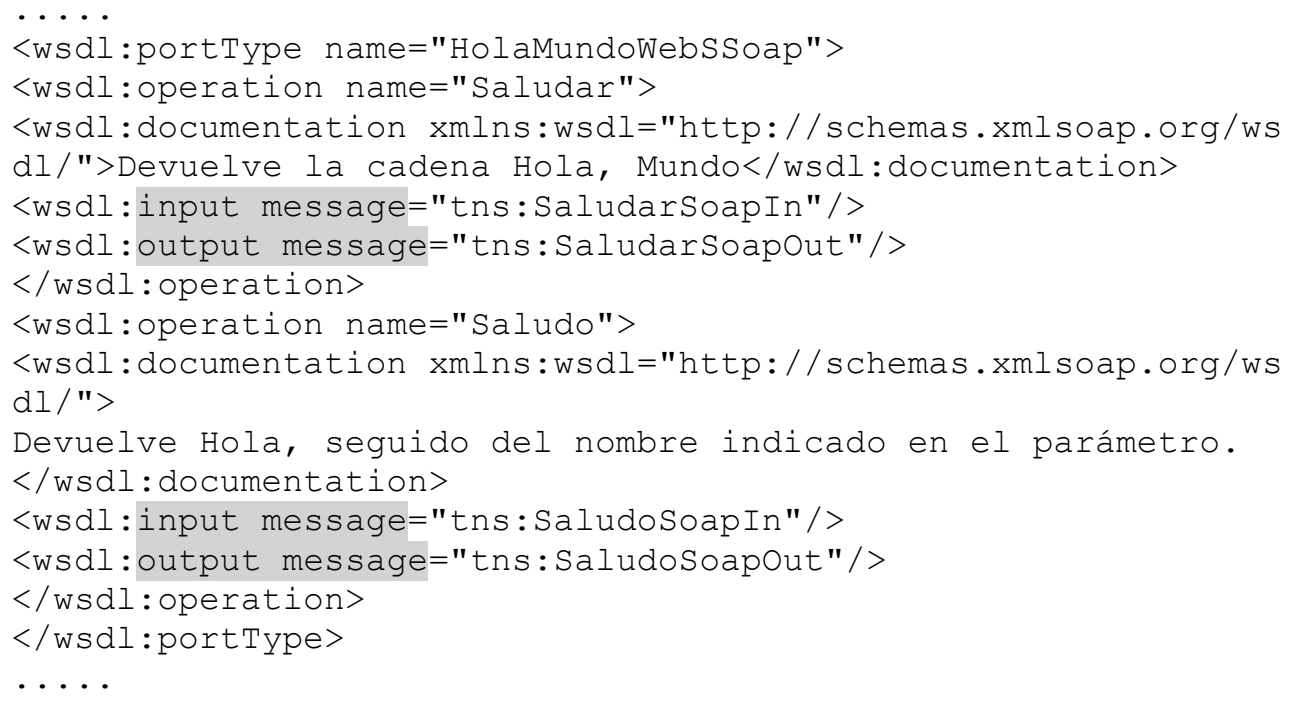

Dapat dilihat, pada dokumen tersebut terdapat 2 input message dan 2 output message. Sehingga, jumlah argument dari baris kode tersebut adalah 4. Selanjutnya, untuk menghitung jumlah APO (Argument per Operation) dengan (1), maka dibutuhkan data jumlah OPS (Operation per Service) dimana jumlah tersebut dapat ditentukan dari banyak pendeklarasian <portType> pada dokumen WSDL.

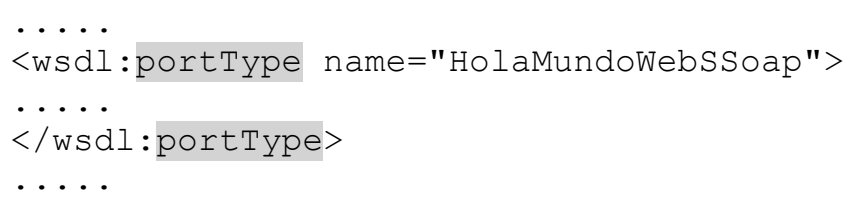

Ditemukan 2 pendeklarasian <portType> pada dokumen, sehingga jumlah OPS didefinisikan sebagai 2. Maka, berdasarkan (1), APO bisa didefinisikan sebagai berikut:

$$
\mathrm{APO}=\frac{\mathrm{n}_{\mathrm{a}}}{\mathrm{n}_{\mathrm{o}}}=\frac{4}{2}=2
$$

Selanjutnya, dicari bobot data atau Data Weight dari dokumen WSDL dimana berdasarkan (2), maka DW (wsdl) didefinisikan sebagai $w \boldsymbol{t}$ karena part berupa <type > pada skema definisi elemennya. 


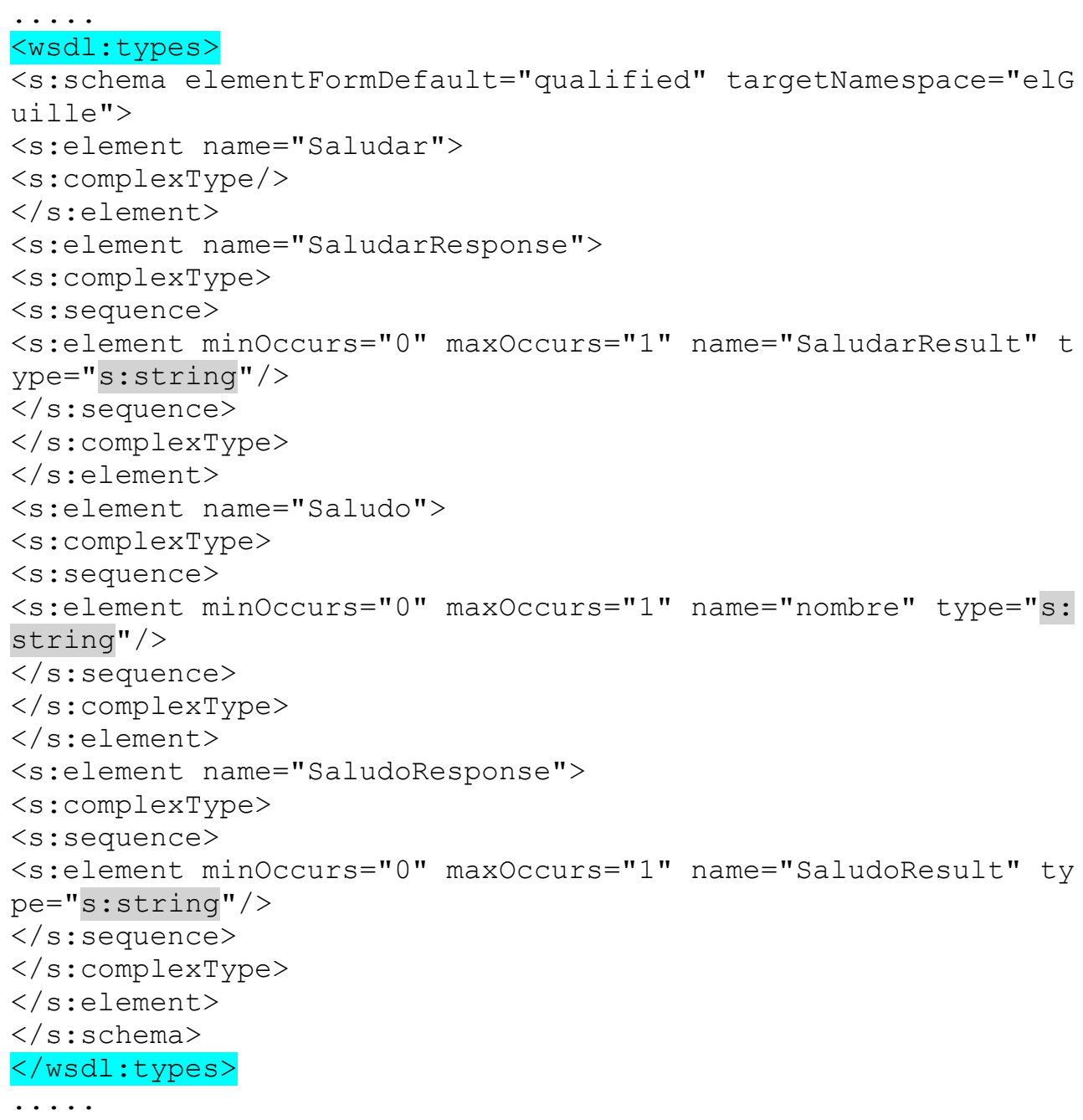

Berdasarkan (7), <type> didefinisikan sebagai complexType atau tipe kompleks, sehingga jumlah $\boldsymbol{w} \boldsymbol{t}=\mathbf{w c}$ dimana $\mathrm{wc}$ didefinisikan sebagai jumlah respon string <s:string $>$, yaitu 3.

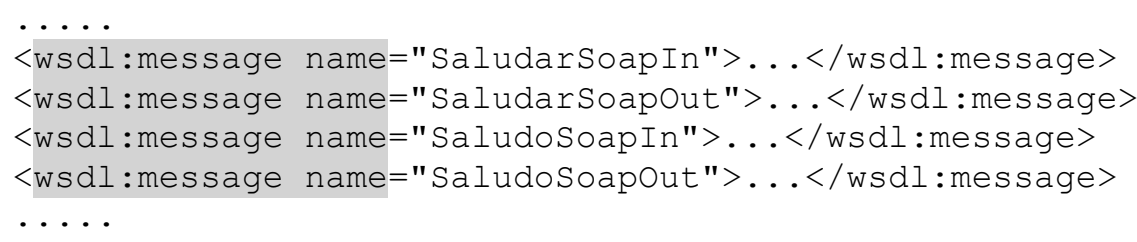

Selanjutnya, banyaknya respon string dijumlahkan dengan banyaknya message berdasarkan baris kode di atas adalah 4. Sehingga, DW(wsdl) didefinisikan sebagai berikut:

$$
\begin{aligned}
& D W(\text { wsdl }) \doteq \sum^{n_{m}} C\left(M_{i}\right) \\
& \quad=\mathrm{C} \text { (“StringResponse") }+\mathrm{C} \text { ("Message") } \\
& \quad=3+4=7
\end{aligned}
$$


Tabel 1. Tabel Hasil jumlah Argument (\#A), OPS, APO, dan DW(wsdl)

\begin{tabular}{|c|c|c|c|c|c|}
\hline \multirow{2}{*}{ ID } & \multicolumn{5}{|c|}{ Penghitungan Metrik Kompleksitas Web Service dengan Penghitungan DW } \\
\hline & Table column subhead & \#A & OPS & $A P O$ & $D W$ \\
\hline 1 & http://www.banguat.gob.gt/variables/ws/BDEF.asmx & 88 & 7 & 12.57 & 144 \\
\hline 2 & $\begin{array}{l}\text { http://www.elguille.info/NET/WebServices/HolaMun } \\
\text { doWebS.asmx }\end{array}$ & 4 & 2 & 2.00 & 7 \\
\hline 3 & $\begin{array}{l}\text { http://in2test.lsi.uniovi.es/sqlmutationws/SQLMutatio } \\
\text { nWS.asmx }\end{array}$ & 8 & 2 & 4.00 & 12 \\
\hline 4 & $\begin{array}{l}\text { http://www.mathertel.de/AJAXEngine/S02_AJAXCo } \\
\text { reSamples/CalcService.asmx }\end{array}$ & 16 & 7 & 2.29 & 30 \\
\hline 5 & $\begin{array}{c}\text { http://www.oorsprong.org/websamples.arendsoog/Ar } \\
\text { endsoogbooksService.wso }\end{array}$ & 33 & 8 & 4.13 & 55 \\
\hline
\end{tabular}

\section{Use Case Diagram}

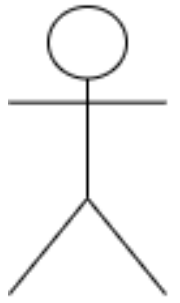

User

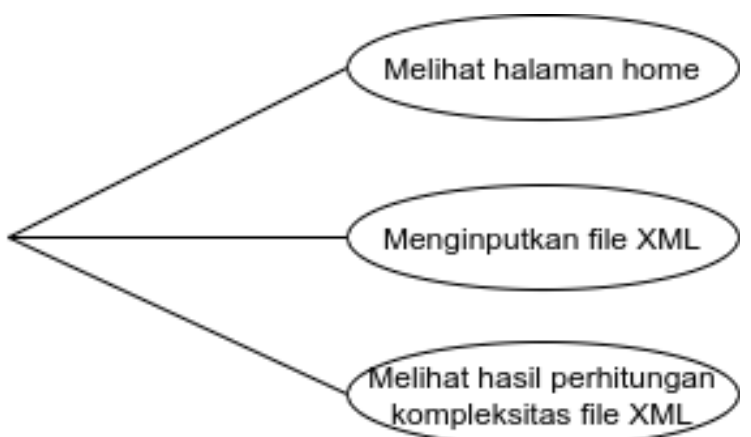

Gambar 3. Use Case Diagram

Tabel 2. Keterangan use case diagram

\begin{tabular}{|c|l|l|}
\hline No. & Use Case & Deskripsi \\
\hline 1. & Melihat halaman home & Merupakan proses menampilkan halaman home \\
\hline 2. & Menginputkan file tipe .xml & Merupakan proses import file dengan tipe .xml \\
\hline 3. & $\begin{array}{l}\text { Melihat hasil perhitungan } \\
\text { kompleksitas }\end{array}$ & $\begin{array}{l}\text { Merupakan proses menampilkan hasil perhitungan } \\
\text { kompleksitas Web Service }\end{array}$ \\
\hline
\end{tabular}




\section{Flowchart (Diagram Alur)}

Setelah dilakukan percobaan secara manual, maka ditentukan alur penghitung metrik skala dan kompleksitas Web Service berdasarkan DW(wsdl) sebagai berikut:

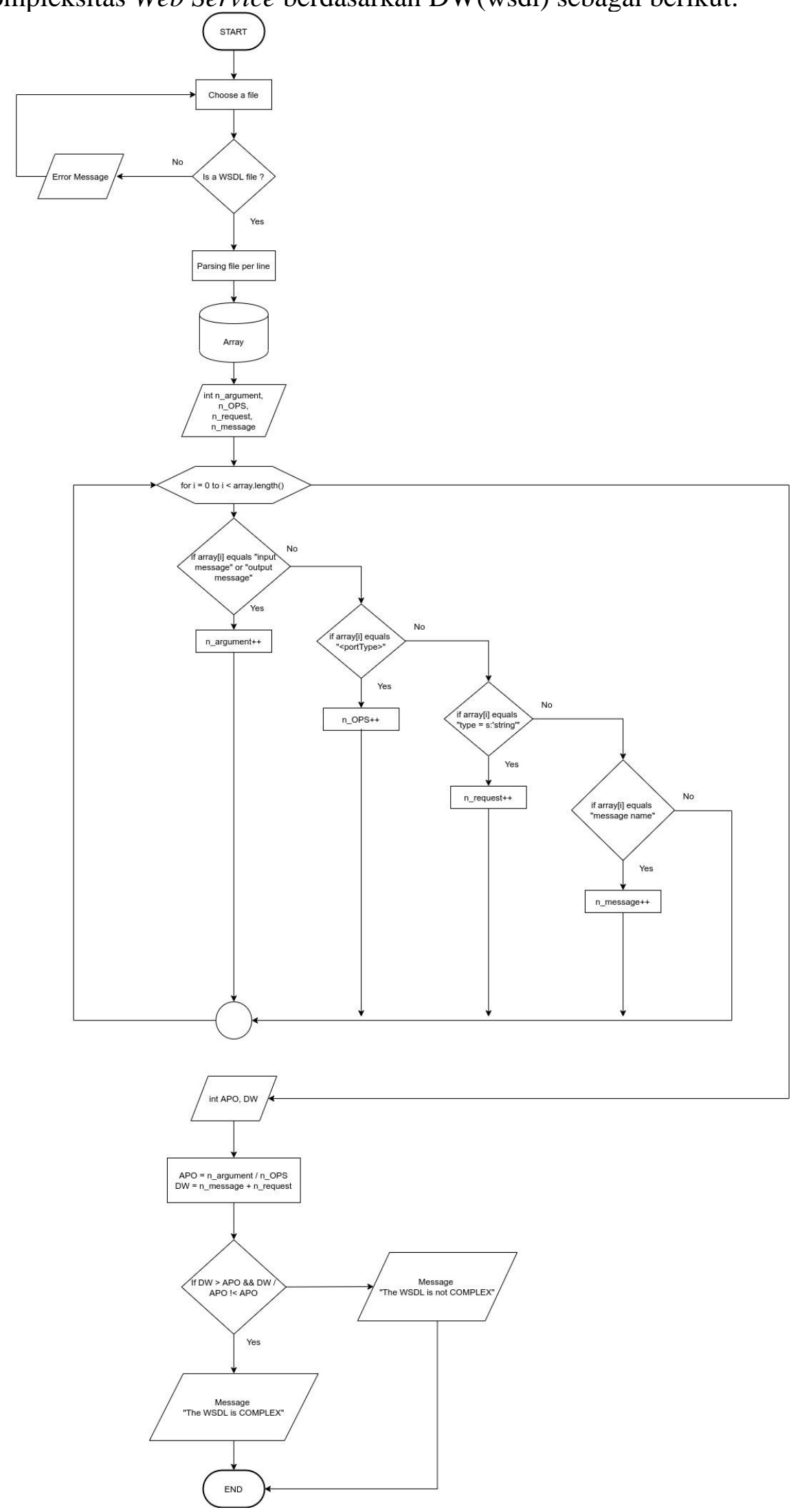

Gambar 4. Diagram Alur Perangkat Lunak 


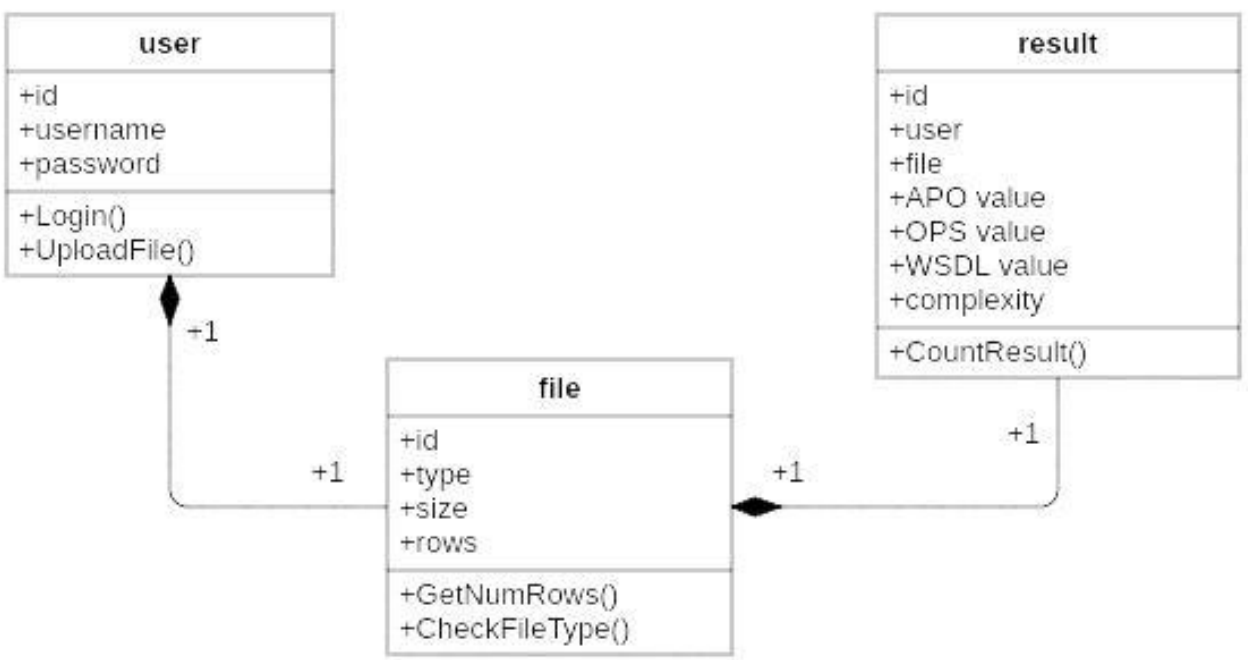

Gambar 5. Class Diagram

Adapun alur proses dari aplikasi ini adalah pertama user di haruskan untuk meng-upload file XML yang akan di hitung kompleksitasnya. Selanjutnya, sistem akan mengecek apakah file yang di-upload oleh user tersebut adalah file berformat .xml atau bukan, jika bukan maka sistem akan menampilkan pop up yang isinya peringatan untuk file yang di upload haruslah berformat .xml. Selanjutnya, file .xml yang sudah di upload oleh user tersebut akan di parsing pada setiap baris dan akan disimpan pada suatu ArrayList. Lalu, dengan konsep looping sebanyak panjang ArrayList akan dilakukan perbandingan dengan mencari beberapa keyword antara lain "input message", "output message", "<portType>". "type = s:string", dan "message name".

Keyword "input message" dan "output message" digunakan untuk mencari argument pada suatu file XML, ketika dalam perbandingan ditemukan keyword "input message" dan "output message" maka nilai jumlah argument bertambah satu. Keyword "<portType>" digunakan untuk mencari Operation Per Service (OPS) pada suatu file XML. Ketika dalam perbandingan di temukan keyword "<portType>", maka nilai jumlah OPS bertambah satu. Keyword "type = s:string" digunakan untuk mencari request berupa respon string pada suatu file XML. Ketika dalam perbandingan ditemukan keyword "type = s:string", maka nilai jumlah request bertambah satu. Keyword "message name" digunakan untuk mencari message pada suatu file XML, ketika dalam perbandingan di temukan keyword "wsdl:message name" maka nilai jumlah message bertambah satu.

Selanjutnya, hasil dari perulangan dan perbandingan di atas dapat digunakan untuk menghitung nilai \#A, nilai OPS, nilai APO, dan DW(wsdl). Adapun rumus perhitungannya adalah sebagai berikut

$$
\begin{array}{ll}
\text { \#A } & =\text { jumlah argument } \\
\text { OPS } & =\text { nilai jumlah OPS } \\
\text { APO } & =\text { \#A / OPS }
\end{array}
$$

Secara sederhana, DW didefinisikan sebagai berikut:

$\mathrm{DW}(\mathrm{wsdl})=$ jumlah request + jumlah message

Dari hasil perhitungan di atas, dapat digunakan acuan apakah suatu file XML tersebut kompleks atau tidak, jika nilai DW(wsdl) / APO tidak kurang dari nilai APO itu sendiri maka file tersebut dapat dikatakan kompleks dan jika sebaliknya maka file tersebut dikatakan belum kompleks. 


\section{Prototype Perangkat Lunak}

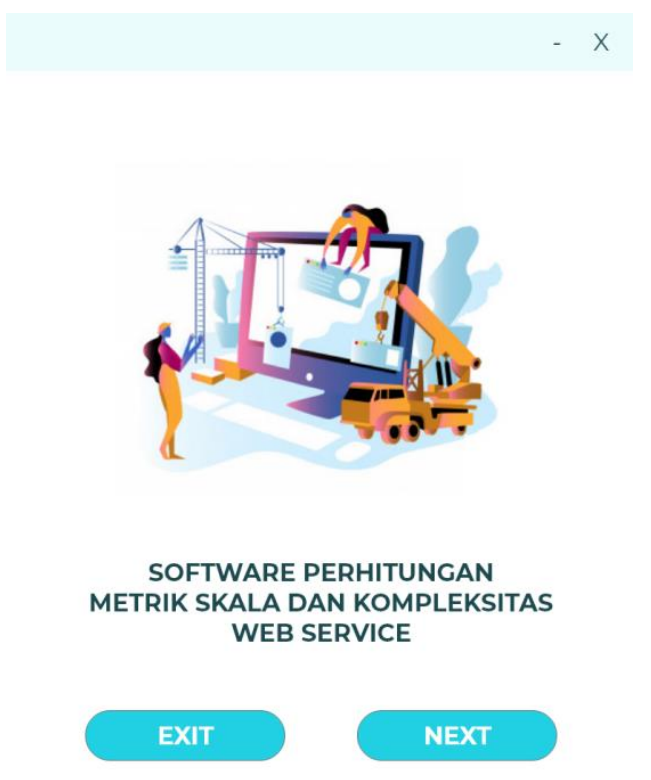

Gambar 6. Tampilan Awal Perangkat Lunak

Tampilan Gambar 6 menunjukkan halaman awal ketika perangkat lunak diaktifkan.

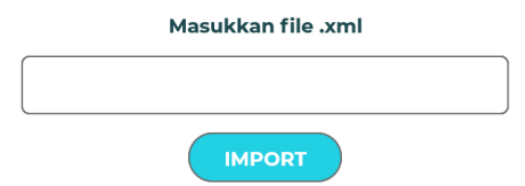

Gambar 7. Tampilan browser dokumen dari komputer

Tampilan Gambar 7 menunjukkan halaman dimana pengguna dapat mengimport file dari komputer. 


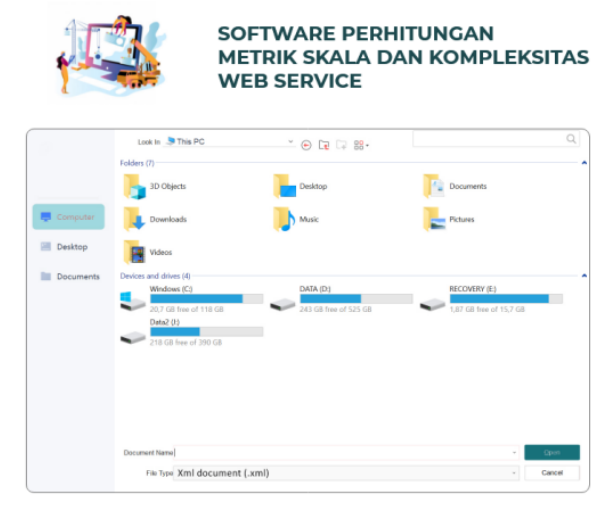

START

Gambar 8. Tampilan browse dokumen dari komputer

Tampilan Gambar 8 ini menunjukkan halaman saat pengguna mengimport file dari komputer.

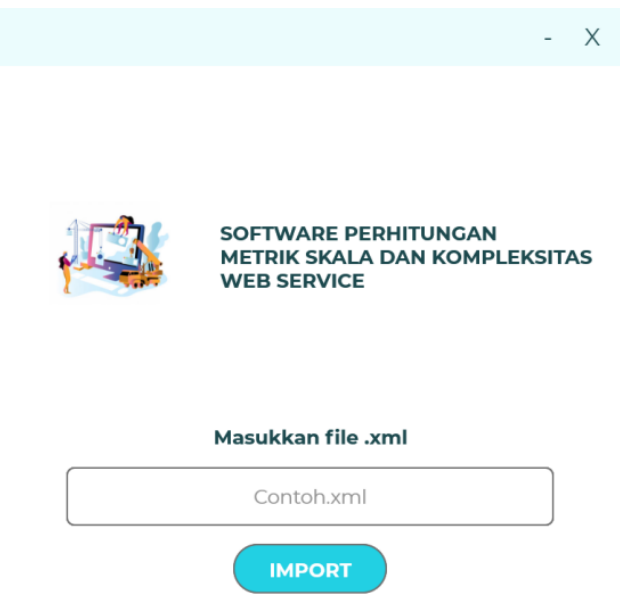

\section{START}

Gambar 9. Tampilan setelah file di import

Tampilan Gambar 9 ini menunjukkan halaman saat pengguna telah mengimport file dari komputer. 


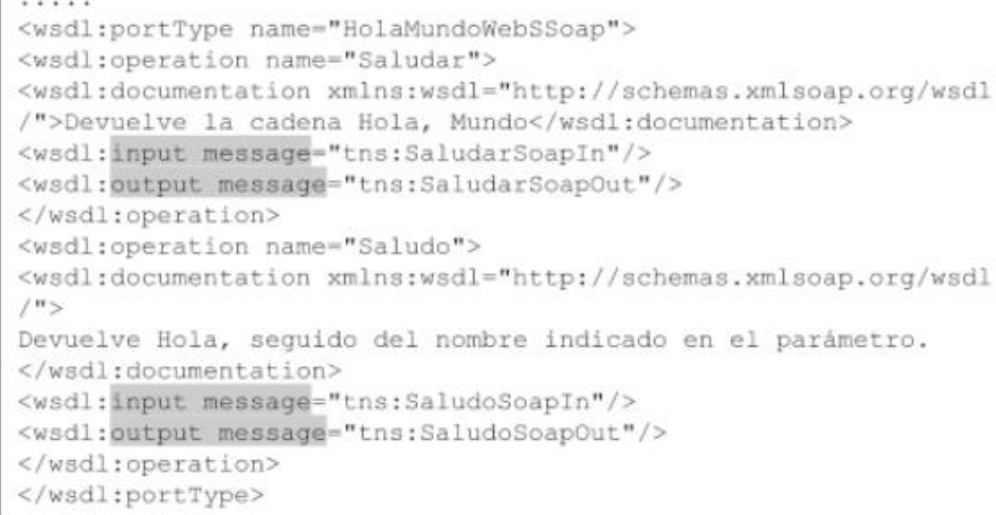

Gambar 10. Tampilan perhitungan argument

Tampilan Gambar 10 menunjukkan perhitungan argument dari dokumen WSDL oleh perangkat lunak perhitungan metrik skala dan kompleksitas Web Service.

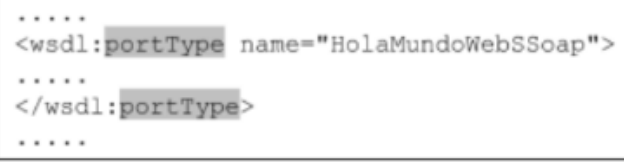

5 Operation Founded per Service $\mathrm{APO}=100 / 5=20$

Gambar 11. Tampilan perhitungan Operation per Service

Tampilan Gambar 11 menunjukkan perhitungan OPS dari dokumen WSDL oleh perangkat lunak perhitungan metrik skala dan kompleksitas Web Service. 


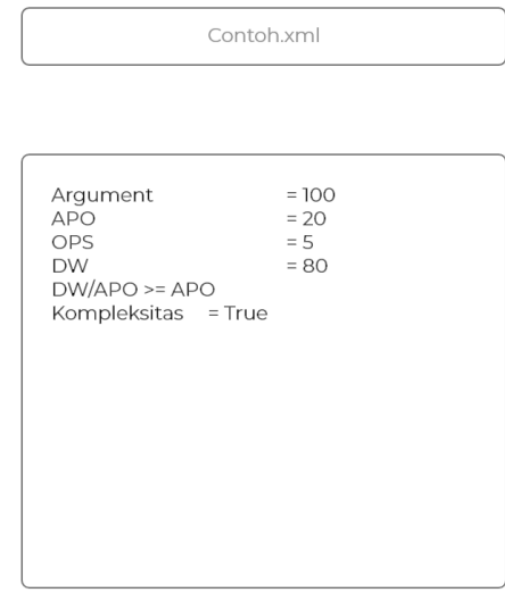

Gambar 12. Tampilan hasil perhitungan Metrik Skala dan Kompleksitas Web Service

Tampilan Gambar 12 menunjukkan perhitungan akhir metrik skala dan kompleksitas Web Service.

Dengan menggunakan sebuah software dalam melakukan perhitungannya, maka dapat menghindari terjadinya human error ketika dilakukan perhitungan secara manual. Hal ini sesuai dengan karakteristik kualitas perangkat lunak, yaitu reliability. Reliability adalah tingkat dimana suatu aplikasi dapat mempertahankan kinerja pada tingkat tertentu ketika digunakan dalam keadaan tertentu.

\section{KESIMPULAN}

Berdasarkan hasil penelitian mengenai analisis dan perancangan software perhitungan matrik skala dan kompleksitas Web Service, dapat diambil kesimpulan sebagai berikut: 1) Sistem dapat menghitung jumlah argument, nilai OPS dan Data Weight WSDL (DW(wsdl)) sebuah file XML yang di-input-kan oleh user. 2) Sistem juga dapat digunakan dalam membandingkan dua atau lebih Web Service dari dokumen WSDL berdasarkan hasil perhitungan DW(wsdl) nya. 3) Perhitungan kompleksitas DW(wsdl) pada file XML dengan software perhitungan metrik skala dan kompleksitas Web Service lebih akurat. Dengan menggunakan sebuah software dalam melakukan perhitungannya, maka dapat menghindari terjadinya human error ketika dilakukan perhitungan secara manual. Dalam penelitian ini, kami telah menganalisis perancangan software perhitungan metrik skalar dan kompleksitas Web Service yang menyajikan metrik yang berfokus pada message yang menggambarkan argument dan operasi untuk menentukan kompleksitas data Web Service. Dengan mempertimbangkan tingkat kompleksitas dari setiap argument, kami telah mengevaluasi langkah-langkah yang dapat memberikan feedback yang berguna bagi developer Web Service maupun pengguna Web Service pada umumnya.

\section{REFERENSI}

[1] Daniel A. Menasce, Virgilio A.F. Almeida, "Capacity Planning for Web Services: Metrics, Models, and Methods”, ISBN-10: 0130659037, ISBN-13: 9780130659033 Prentice Hall, 2001.

[2] Basci, D., \& Misra, S, "Data complexity metrics for XML Web Services", Advances in Electrical and Computer Engineering, vol. 9(2), pp. 9-15, 2009. 
[3] Aznag, M., Quafafou, M., Durand, N., \& Jarir, Z., “Web Services Discovery and Recommendation Based on Information Extraction and Symbolic Reputation", International Journal on Web Service Computing, vol. 4(1), pp. 1-18, 2013.

[4] Widyawati, Priyambadha, B., Pradana, F., "Kakas Bantu Perhitungan Kompleksitas Perangkat Lunak Menggunakan Metrik Cognitive Weighted Inherited Class Complexity", Jurnal Pengembangan Teknologi Informasi dan Ilmu Komputer, vol. 3(5), pp. 5201-5206, 2018.

[5] Widyaningtyas, Y., Arwan, A., \& Rusdianto, D. S., "Perhitungan Ukuran Kompleksitas Fungsional Perangkat Lunak Dengan Metrik Function Point”, Teknologi, vol. 6(1), pp.38, 2016.

[6] Hapsari, R. K., Husen, M. J., "Estimasi Kualitas Perangkat Lunak Berdasarkan Pengukuran Kompleksitas Menggunakan Metrik Function Oriented”, Seminar Nasional Sains dan Teknologi Terapan III 2015 Institut Teknologi Adhi Tama Surabaya.

[7] Riza, A., Anshori, M. A. I., Arrazy, F., and Yaqin, M. A., "Pengukuran Metrik Kompleksitas Web Service Sekolah", Jurasik (Jurnal Riset Sistem Informasi Dan Teknik Informatika), vol. 5(1), pp. 148, February 2020.

[8] Risdia Wulan, F., Ainul Yaqin, M., \& Zaman, S., "Dekomposisi Web Service pada Enterprise Resource Planning Pondok Pesantren.", Konferensi Nasional Sistem Informasi 2018, vol. 8-9, 2018.

[9] Soni, A., \& Ranga, V., “API features individualizing of Web Services: REST and SOAP”, International Journal of Innovative Technology and Exploring Engineering, vol. 8(9 Special Issue), pp. 664-671, 2019.

[10] Ladan, M., "Web Services: Technologies and Benefits”, Journal of Communication and Computer, ISSN 1548-7709, Number 6,Volume 7, 2010.

[11] Ladan, M. I., "Web Services Metrics: A Survey and A Classification”, IPCSIT (International Proceedings of Computer Science and Information Technology) Singapore, vol. 11, pp. 93-98, 2011 [International Conference on Network and Electronics Engineering, 2011].

[12] Y.Yu, J.Lu, J.Fernandez-Ramil, P. Yuan,"Comparing Web Services with other Software Components", Proceeding of IEEE International Conference on Web Services (ICWS 007).

[13] Sasmito, G. W., "Penerapan Metode Waterfall Pada Desain Sistem Informasi Geografis Industri Kabupaten Tegal", Jurnal Informatika:Jurnal Pengembangan IT (JPIT), vol. 2(1), pp. 8, January 2017.

[14] Pressman, R.S., Rekayasa Perangkat Lunak: Pendekatan Praktisi (Buku Dua), Yogyakarta: Penerbit Abadi. 2002.

[15] Informatika, Praktikum Rekayasa Perangkat Lunak Jurusan Teknik Informatika, Jurusan Teknik Informatika UIN Malang, 2017.

[16] Akkiraju, R., Farrell, J., Miller, J., Nagarajan, M., Sheth, A., \& Verma, K., "Web Service Semantics WSDL-S.", W3C Workshop on Frameworks for Semantics in Web Services, 2005.

[17] Setiawan, Adnan, "Perancangan XML Web Services Untuk Pelaporan Transaksi Data Distribusi Obat Pada Instalasi.", Makalah Seminar Tugas Akhir.

[18] Fauzan, A. C., Sarno, R., and Machfud, I., "Simulation of Agent-Based and Discrete Event for Analyzing Multi Organizational Performance." 2019 International Seminar on Application for Technology of Information and Communication (iSemantic). IEEE, 2019.

[19] S. Najah, M. Ainul Yaqin, L. S. Angreani, and A. C. Fauzan, "Mengukur Akurasi Query Pada Interface Repository Menggunakan User Interface (UI) Discovery Berbasis Software as a Service (SAAS)," BRILIANT J. Ris. dan Konseptual, vol. 4, no. 1, pp. 206-214, 2019, doi: http://dx.doi.org/10.28926/briliant .v3i4.312.

[20] S. Najah, M. Ainul Yaqin, L. S. Angreani, and A. C. Fauzan, "User Interface (UI) Discovery Application To Measure Query Accuracy On Interface Repository” Journal Of Development Research, vol. 3, no. 1, pp. 1-6, 2019. 